\title{
Water and Surfactant Flooding in Low Permeable Chalk Studied by X - Ray CT Scanning
}

\author{
* Stenby E. H., ** Engstroem F., *** Bieber M. T., Hansen T. 0. \\ * Techn. University of Denmark \\ ** Maersk Olie og Gas A. S., Denmark \\ *** IFP, France
}

\begin{abstract}
Copyright 1995, Stoering Committes of the European IOR - Symposium.
This paper was presented at the 8th. European IOR - Symposium in Vienna, Austrla, May 15 - 17. 1995

This paper was selected for presentation by the Steering Committes, following reviow of information contained in an abstract submitted by the outhor(s). The paper. os presented has not been reviowed by the Steering committee.
\end{abstract}

\section{ABSTRACT}

Displacement processes of oil by water in lowpermeable reservoir chalk from the Danish part of the North Sea have been studied by use of $x-$ ray $\mathrm{CT}$-scanning. The chalk is characterized by its low permeability, i.e. 0.1 to $10 \mathrm{mD}$, and its relatively high porosity, i.e. $20-45 \%$. The influence of the following parameters has been investigated: initial saturations, viscosity ratio, interfacial tension, and flow rate. The information obtained by x-ray CT-scanning, which is not available from an ordinary massbalance monitoring, including: a) The influence of rock heterogeneity on initial fluid saturations and the displacement process. b) The dominating character of the capillary end effects in experiments with high interfacial tension.

c) A correct interpretation of the results at low interfacial tension which is a combination of increased microscopic displacement efficiency and a reduction of the capillary end effect.

\section{INTRODUCTION}

Prior to the implementation of any. new secondary or tertiary oil recovery process (water injection, gas injection, surfactant injection, etc.) it is customary for the oil companies first to investigate the potential microscopic recovery efficiency of the process by a dedicated core analysis programme. In case the core analysis results are encouraging, then the macroscopic recovery efficiency is assessed by a reservoir simulation study. The accuracy of the performed core analysis is therefore crucial for a correct evaluation of different oil recovery processes.

Core analysis test procedures originate in many cases from the experience obtained by the testing of high-permeable clean sandstones. Although these procedures may be applicable to high-permeability sandstones, experience has shown that the test procedures may not produce reliable results in general. The reason being that the conditions necessary for a valid interpretation of the tests, i.e. constant saturation before and after the test, limited capillary end effects, etc. cannot be created for some reservoir rocks without causing unrealistic pressure gradients, movements of fines, and/or sample deformation due to plastic deformation of the core material during testing.

Cores of low-permeable North Sea chalk are a rock type where the validity of the current core analysis procedures can be questioned.

The basis for this paper is experimental work performed at Institut Français du Petrole (IFP). 
The objective of the work was to validate the potential of $\mathrm{x}$-ray CT-scanning to monitor oil recovery processes in tight chalk. The recorded saturation data is, however, sufficient to illustrate that the basic assumptions for core analysis interpretation must often be considered to be violated in connection with tests on North Sea chalk.

The strong influence of small scale heterogeneities and capillary end effects are also clearly illustrated in a surfactant flooding experiment.

\section{EXPERIMENTAL SET-UP}

The core material was plugs of reservoir rocks from the North Sea. The properties of the rock samples are given in the following section. The plugs used for the experiments described in this work were cylinders of either 2.5 or $3.8 \mathrm{~cm}$ in diameter and approximately $7 \mathrm{~cm}$ long. In order to flood the plugs they were coated with Araldite except on the end surfaces. End plates with a distribution pattern of concentric circles were used. The $\mathrm{x}$-ray CT-scanner at IFP was used. The instrument was a CGR medical scanner model CE12000 with a spatial resolution better than $0.5 \mathrm{~mm}$. The following procedure was applied to prepare the plugs for the flooding experiments:

- $\quad$ Scanning of dry, evacuated plug

- Saturation with brine under vacuum

- Scanning of brine-saturated plug to obtain basic data, e.g. porosity distribution before the flood test.

Displacement with oil until no water production

Displacement with brine. Monitored by frequent scanning

Cleaning with iso propanol at $2 \mathrm{ml} /$ hour for 48 hours

Cleaning with brine at $2 \mathrm{ml} /$ hour for a minimum of 72 hours

Scanning to confirm $100 \%$ brine saturation

The following experimental parameters were varied: oil viscosity, flow rate during oil saturation, flow rate during waterflooding, and interfacial tension by addition of a surfactant to the brine.

The plug was placed horizontally and no influence of gravitational forces was observed. The displacement process was monitored by scanning several parallel, vertical cross-sections along the flow direction. Image analysis software developed at IFP was used to obtain the porosity distribution of the rock sample as well as the oil and brine saturation for each scan during the flooding experiments.

It was possible to distinguish oil and brine without adding special compounds to increase the $\mathrm{x}$-ray attenuation in one of the phases. The brine was a synthetic sea water solution mixed with a synthetic reservoir brine in the ratio two to one. The surfactant used for comparison with the water floods was an anionic surfactant from HOECHST, DODIFLOOD B-1320. As oils the commercial oils Soltrol 130 and Albelf were used in different mixing ratios. Some physical properties of the oils are given in Table 1.

Table 1. Physical properties of the model oils.

\begin{tabular}{||l|l|c|c||}
\hline Oil & Mixture & $\begin{array}{l}\text { Viscosity } \\
(\mathbf{c P})\end{array}$ & $\begin{array}{c}\text { Density } \\
\left(\mathbf{g} / \mathbf{c m}^{3}\right)\end{array}$ \\
\hline Oil-1 & Soltrol 130 & 1.55 & 0.755 \\
\hline Oil-2 & $\begin{array}{l}\text { Soltrol 130 } \\
- \text { Albelf } \\
(60: 40)\end{array}$ & 7.17 & 0.803 \\
\hline Oil-3 & $\begin{array}{l}\text { Soltrol 130 } \\
- \text { Albelf } \\
(20: 80)\end{array}$ & 72.1 & 0.846 \\
\hline
\end{tabular}

The interfacial tension was different between the brine and the different oils. The values are given in Table 2.

\section{CORE MATERIAL}

The core plugs used in the experiments discussed in this paper were drilled from a 60 $\mathrm{cm}$ piece of core of late Maastrichtian age. The rock porosity for the selected interval varies 
from 38 to $41 \mathrm{pu}$ and air permeability varies from 6.3 to $10 \mathrm{mD}$. The selected interval can therefore be considered to be rather homogenous with respect to porosity and permeability. Klinkenberg permeability varies from 3.8 to 6.3 $\mathrm{mD}$. These permeabilities are as expected for a matrix permeability dominated, late Maastrichtian chalk, given the porosity level.

The lithology of the core interval is characterized as a finely laminated, only slightly burrowed/ bioturbated, somewhat fractured chalk with a few scattered pyrite grains. The fractures are mainly indistinct hairline fractures, although a few apparently closed $1 \mathrm{~cm}$ long fractures (tension gashes) are seen in connection with a stylolite at the base of the core interval.

The core plug used in the water injection CTscanning experiments (plug 3 ) was originally cut as a long (> $7.5 \mathrm{~cm}), 2.5 \mathrm{~cm}$ diameter, horizontal plug from the upper part of the core piece. After cleaning of the plug, the porosity $(40.50 \mathrm{pu})$, the Klinkenberg permeability (5.6 $\mathrm{mD}$ ), and two air-brine drainage capillary pressure curves were determined. Although the two capillary curves agree well, the later analysis has indicated that the actual irreducible water saturation is in the order of $2 \%$ rather than $8 \%$, as the experiments indicated. The too high irreducible water saturation is most likely a consequence of insufficient stabilization time. In the case of chalk several weeks up to months are needed at each pressure level.

After plug 3 had been mounted in Araldite the length of the plug was reduced to $5.88 \mathrm{~cm}$. The average porosity and brine permeability was then $39 \mathrm{pu}$ and $6.2 \mathrm{mD}$, respectively. The average porosity of the plug seems to have been reduced moderately while the permeability has been slightly increased. By comparison to average petrophysical correlations for late Maastrichtian chalk it can be concluded that the plug prior to mounting in Araldite could be considered as representative of typical matrix permeability for late Maastrichtian chalk and that the preparation and mounting has not changed its properties significantly.
Plug 1, which was used for the surfactant injection test, had a permeability of $6.8 \mathrm{mD}$ and a porosity of $29.3 \mathrm{pu}$. The length was $8.1 \mathrm{~cm}$ and diameter was $3.8 \mathrm{~cm}$.

\subsection{Porosity Distribution}

The porosity distribution along the plugs was inferred from the CT-scans.

Although the sample used in tests 3.1 to 3.8 was expected to be a rather homogenous sample according to the core description, it is evident, from the CT-based porosity distribution, that two low-porosity layers penetrate the sample. As will be described later, this affects the flow. Changes in the porosity distribution with time due to the flow processes will also be discussed.

At the beginning of the test sequence, the sample can be viewed as $40-41$ pu porosity chalk intersected by two low-porosity layers (approximately $35 \mathrm{pu}$ in average). This description is the basis for the simplified porosity model illustrated in Figure I. Average porosity recorded on the sample is $38.9 \mathrm{pu}$ and the average porosity of the simplified porosity model is in agreement with this. The simplified porosity model is the basis for the further modelling work described below.

The porosity distribution in plug 1 was significantly more complex and a variation of more than 20 pu is observed.

\section{DISPLACEMENT EXPERIMENTS}

\subsection{Test Procedure}

Eight oil-water and water-oil displacement tests were performed on plug 3 . All tests started by reducing the water saturation by the injection of oil and thereafter displacing the oil by water injection. For the first six tests, plug 3 was cleaned and resaturated with water prior to testing, while the sample was not cleaned after tests 3.6 and 3.7. Tests 3.1 to 3.6 are therefore primary drainage/primary imbibition experiments while 3.7 and 3.8 are secondary drainage/imbibition experiments. 
Table 2. Waterflooding test conditions. 1) During oil injection. 2) During water injection

\begin{tabular}{||l|l|l|l|l|l||}
\hline $\begin{array}{l}\text { Test } \\
\text { no. }\end{array}$ & $\begin{array}{l}\text { Cleaned } \\
\text { before } \\
\text { test }\end{array}$ & $\begin{array}{l}\text { Oil } \\
\text { flow rate } \\
(\mathbf{m l} / \mathbf{h})\end{array}$ & $\begin{array}{l}\text { Oil } \\
\text { viscosity } \\
(\mathbf{c P})\end{array}$ & $\begin{array}{l}\text { Oil-water } \\
\text { interfacial } \\
\text { tension } \\
(\mathbf{m N / m})\end{array}$ & $\begin{array}{l}\text { Water } \\
\text { flow rate } \\
(\mathbf{m l} / \mathbf{h})\end{array}$ \\
\hline 3.1 (Oil-1) & yes & 12 & 1.55 & 29.07 & 4 \\
\hline $3.2($ Oil-1) & yes & 12 & 1.55 & 29.07 & 4 \\
\hline $3.3($ Oil-1) & yes & 12 & 1.55 & 29.07 & 8 \\
\hline $3.4($ Oil-3) & yes & 1 & 72.10 & 6.22 & $-1)$ \\
\hline (Oil-1) & & - & 1.55 & 29.07 & $82)$ \\
\hline $3.5($ Oil-2) & yes & 4 & 7.17 & 6.58 & 4 \\
\hline $3.6($ Oil-2) & yes & 4 & 7.17 & 6.58 & 3 \\
\hline 3.7 (Oil-2) & no & 4 & 7.17 & 6.58 & 4 \\
\hline 3.8 (Oil-2) & no & 4 & 7.17 & 6.58 & 3 \\
\hline
\end{tabular}

The oil injection rate during drainage, oil viscosity, oil-water interfacial tension, and water injection rate during imbibition were varied as given in Table 2. After the injection of the viscous oil (Oil-3) in test 3.4, the injected oil was replaced by Oil-1 by miscible displacement, prior to water injection.

Two experiments were carried out in order to investigate the effect of adding a surfactant to the injection water. These experiments are described in detail separately below.

The oil injection was in all cases continued until apparently no more water was produced at the outlet end over a long period of time. No rigorous control of the lack of water production or recording of oil injection pressure, injection time, etc. was in view of the basic purpose of the flooding experiments. The main goal was to investigate the capabilities of CT-scanning.
A CT-scan was made after the initial oil injection phase in order to record the water saturation profile prior to waterflooding. After this initial CT-scan waterflooding was initiated. CT-scans were made recording the changing oil saturation with time during the water injection phase. Waterflooding was terminated after 1000 minutes of water injection.

The basic results of tests $3.2,3.4$, and 3.8 are shown in Figure la-c. This figure shows the oil saturation as function of the distance from the inlet of the plug and of the injected volume of water. The injected water volume is expressed relatively to the movable hydrocarbon volume (hydrocarbon volume in plug prior to water injection minus hydrocarbon volume left in the plug after termination of water injection). 


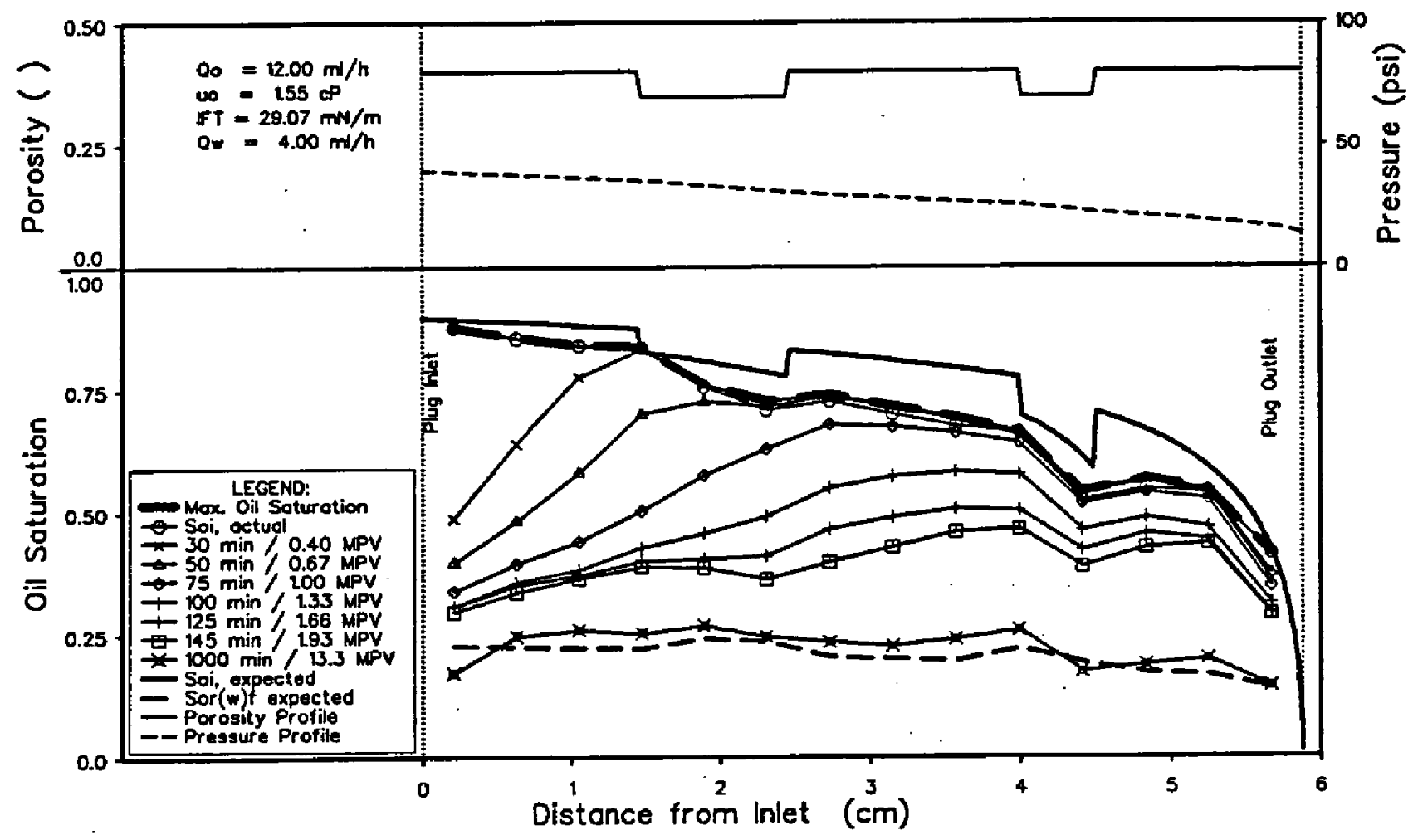

Figure 1A Oil Saturation vs Length, Test 3.2 Drainage/Imbibition by Oil/Water injection Maostrichtian Chalk, 39\% Porosity

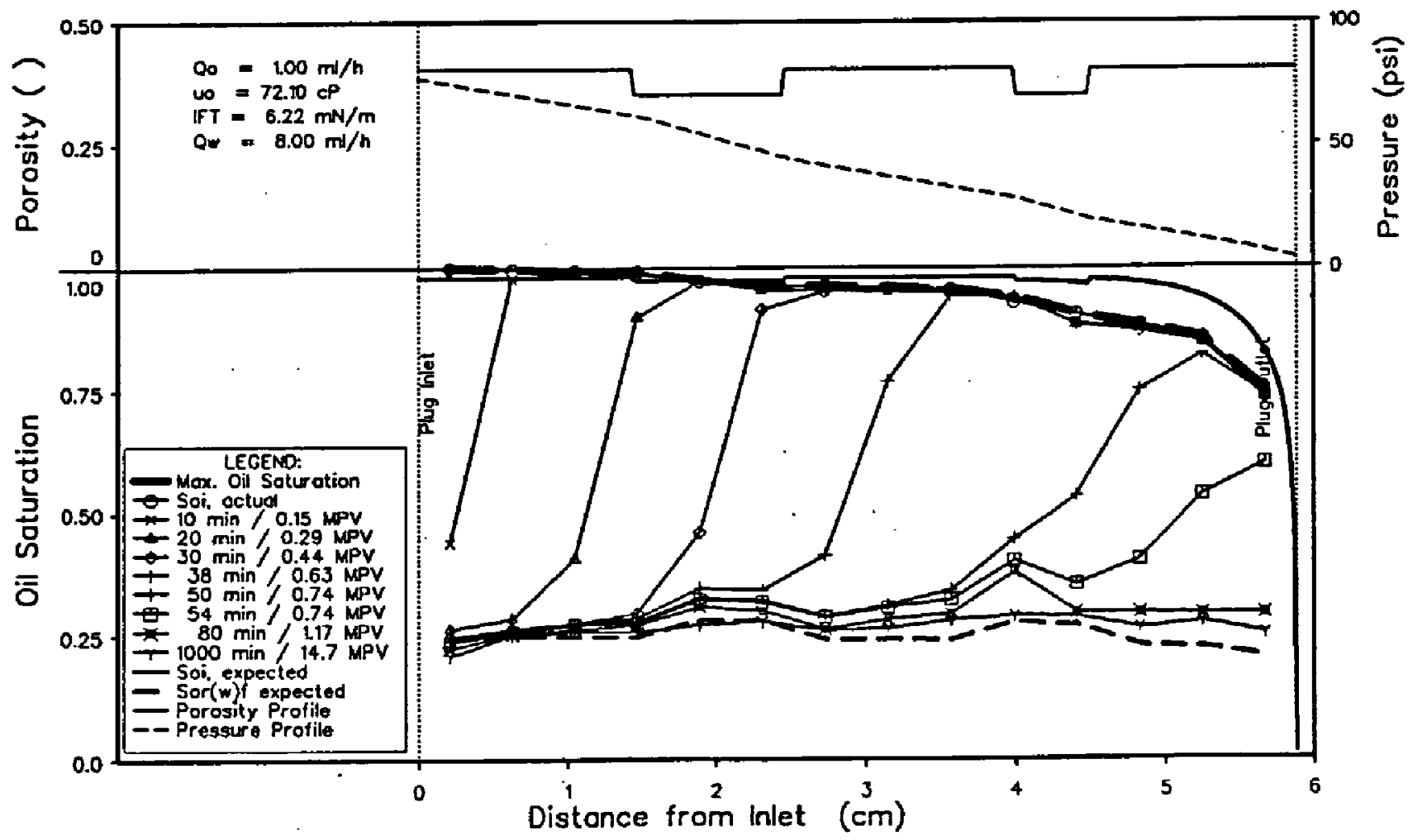

Figure 18 Oil Soturation vs Length, Test 3.4 Drainage/Imbibition by Oil/Water Injection Maastrichtian Chalk, 39\% Porosity 


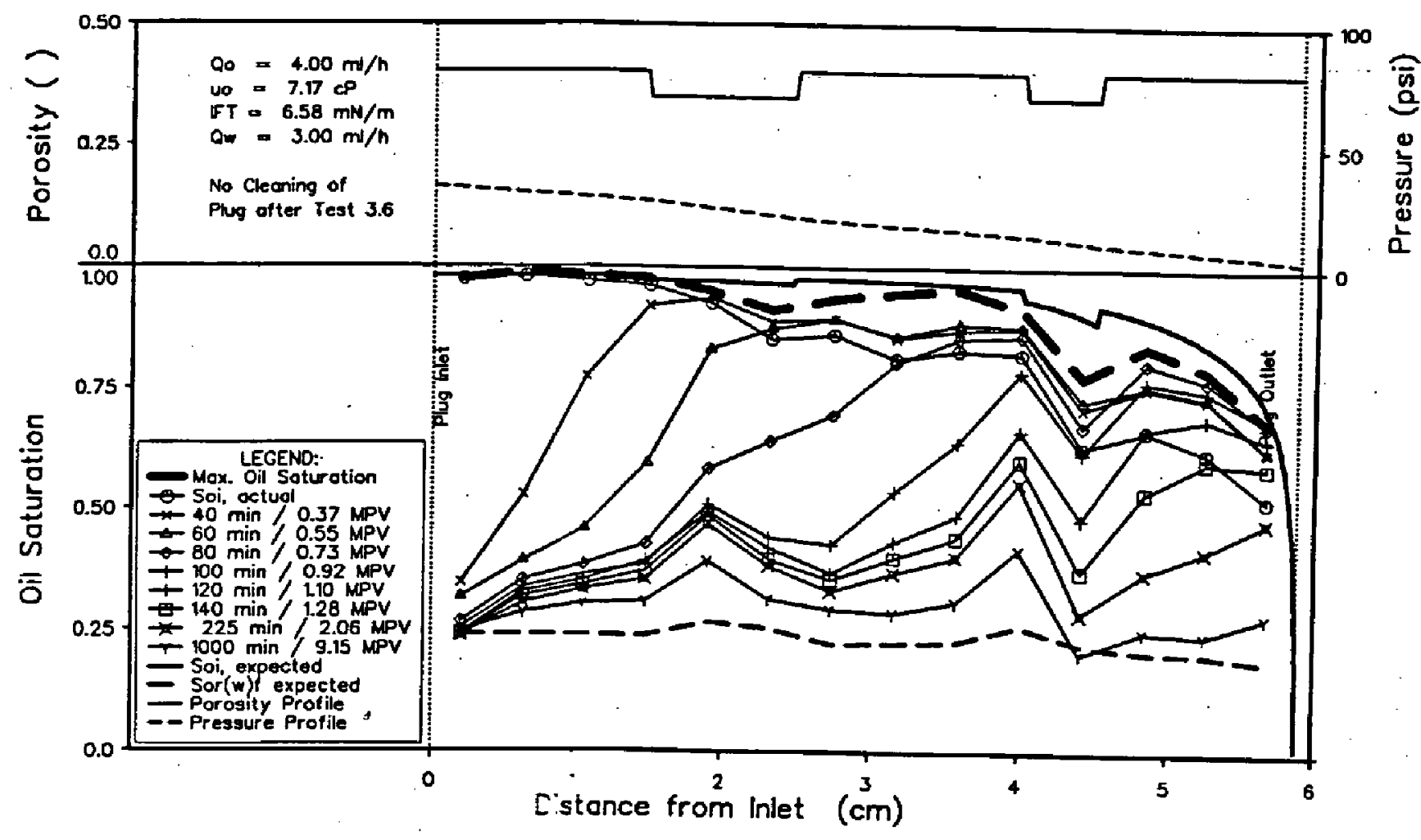

Figure 1C Oil Saturation vs Lenght, Test 3.8 Drainage/Iribibition by Oil/Water Injec. Maastricition Chalk, 39\% Porosity

\subsection{Modelling of Test Results}

The oil injection phase was modelled br ' ise of the simplified porosity model, the cruilary pressure, and relative permeability moreis of Maastrichtian chalk. The model assums that water is immobile and in drainage equiiitrium with the moving oil phase at the end oil the oil injection phase.

The oil pressure at the downstream enc is the plug is thus assumed to be equal to the canilary entry pressure for a 40.5 pu Maastrichtiar sialk scaled by the interfacial tension of the oi--vater system. Equilibrium water saturation tiszerore reaches its maximum at the downstreen end decreasing gradually towards the upstre $=$ end. The change in water saturation is contrci $2 \mathrm{~d}$ by the increase in oil pressure, which is yain controlled by the oil flow rate (Table 2 ) $z$ a the drainage oil relative permeability.
The expected equilibrium oil saturation at the end of the water injection phase was predicted by $a$ model that links the remaining oil saturation after waterflooding for Maastrichtian chalk with porosity and maximum oil saturation ever. In the case of tests 3.2 to 3.6 the maximum oil saturation is equal to the maximum oil saturation at any given point during the waterflood including the initial oil saturation profile. In the case of tests 3.7 and 3.8 the maximum oil saturation is the maximum oil saturation at any given point since the plug was last fully cleaned prior to test 3.6.

\subsection{Initial Saturation Profile}

A comparison was made of the expected and the actual oil saturation profiles $\left(\mathrm{S}_{\text {oi,expected }}\right.$ and $\mathrm{S}_{\text {oi,actual }}$ in Figure 1) after the initial oil injection phase for tests 3.2 to 3.8. This comparison illustrates that the "expected $\mathrm{S}_{\mathrm{oj}}$ " curve is an upper bound curve for the "actual $S_{\mathrm{oi}}$ " curve. The expected 
and especially the actual water saturation indicate significant variations in the water saturation along the plug. Finally, the presence of the two low-porosity bands within the tested plug is clearly reflected in the saturation profiles.

That the expected $\mathrm{S}_{\mathrm{oi}}$ curve is indeed an upper bound curve for the actual $S_{o i}$ curve can be inferred from the fact that the drainage relative permeability to water for chalk is dropping rapidly for decreasing water saturation and is less than 0.01 for water saturations below 20$30 \%$. It may even be less than 0.001 , as indicated by drainage relative permeability tests on chalk. An estimate of the time required to reduce the water saturation from $25 \%$ to $2 \%$ at the flow conditions, plug size, etc. for tests 3.2 to 3.8 , indicates that it may take from 1 day to 5 weeks to reduce an average $25 \%$ water saturation to irreducible water saturation. Based upon the actual flow conditions the time required is shortest for test 3.4 while it may be four times longer for tests 3.2 and 3.3. Actual oil injection time is therefore clearly less than the time required to drive the water saturation down to drainage equilibrium.

Variations in the expected, initial water saturation profile can - in particular for tests 3.2 and 3.3 - be explained by an insufficient injection pressure. The injection pressure must be significantly higher than the capillary entry pressure for the capillary transition zone to be of insignificant length relative to the plug length.

Finally, the observed effects on the saturation curve of the low-porosity bands can be explained by the increased capillary entry pressure for these zones in combination with a higher irreducible water saturation.

\subsection{Water Injection}

An inspection of the oil saturation profiles during the water injection phase (Figure 1a-c) reveals that the water injection only in the case of test 3.4 established a clear oil-water front that moved through the sample in response to the water injection. The lack of a stable oil-water front in the other six tests - and at the end of test 3.4 - is considered to be a combination of insufficient flow rate to reduce the effects of water imbibition to an insignificant level (tests 3.2 and 3.3), decreasing initial oil saturation at the downstream end of the plug (all tests, but especially visible in tests 3.3 and 3.4 ), and the increasing barrier effect of the two low-porosity bands after the fines migration during test 3.4. The latter seems to have reduced the porosity in the central parts of these bands to approximately $32 \mathrm{pu}$ (tests 3.5 to 3.8 ).

It is also interesting to notice that the oil saturation in general does not increase at any point during the water injection. The only exceptions being tests 3.5 and 3.8 where the oil saturation increases slightly at the downstream end during the initial parts of the water injection. The oil tends therefore to displace oil ahead of the oil-water front.

By reference to Figure 1 frontal stability seems to exist as long as the foremost part of the oilwater front does not enter into the part of the plug where the initial water saturation exceeds $25-30 \%$. In those cases (see e.g. test 3.2 ) a water finger is advancing ahead of the oil-water front. The observed water finger could in principle be caused by frontal instability. However as the water mobility in all the tests is less than that of the oil, this explanation does not seem to be plausible. A more likely explanation is that when the oil-water front moves into a part of the plug where the drainage water saturation is more than $25-30 \%$ then the relative permeability to water reaches a value significantly above zero, which allows the water to be moved ahead of the stable front.

\subsection{Sample Alterations}

From porosity maps made between the flooding experiments it is clear that the structure of the porous medium is changing as a result of the fluid flow through. The changes in the porosity distribution do not lead to a significant change in the average porosity or result in a change in the absolute permeability. From these experiments it appears that the change in rock 
structure is caused by flooding with the viscous oils. In experiment 3.4 , where the oil viscosity was $72.1 \mathrm{cP}$ the high-porosity bands became even more porous and the downstream lowporosity bands became even tighter. The maximum porosity increased by approximately $10 \mathrm{pu}$ and the minimum porosity decreased by approximately $10 \mathrm{pu}$. The general flow pattern was not affected but the tendency of pool formation of oil in the high-porosity bands and strong water imbibition in the tight bands became more pronounced in the later experiments.

The pressure drop across the tested sample achieved its maximum value during the oil injection phase of test 3.4. This is a consequence of the high viscosity of Oil-3 utilized in this test to establish the lowest possible value of the initial water saturation. Although the maximum pressure drop did not exceed 200 psi and therefore can not be called excessive, it seems still to have been sufficient to mobilize fines within the sample. The movement of fines seems therefore to have enhanced the porosity heterogeneity within the sample by moving particles from upstream of the low-porosity bands to the middle to downstream side of the low-porosity bands.

\subsection{Remaining Oil Saturation Profile}

A comparison of the expected remaining oil saturation profile (expected $\mathrm{S}_{\mathrm{or}, \mathrm{w}, \mathrm{f}}$ ) and the actual oil saturation profile after the injection of a water volume equal to 9.1 to 14.5 times the movable oil volume indicates that the expected and actual profiles agree rather well for the tests in general.

The agreement is best for tests 3.2 to 3.4 where the main difference, if any, is a slightly higher actual remaining oil saturation at the downstream end of the plug compared to the expected. The applied remaining oil saturation model seems therefore capable of correctly predicting both the remaining oil saturation level and the decrease in the remaining oil saturation towards the end of the plug. The latter caused by the decrease in the initial oil saturation.
After test 3.4 the agreement between the expected and actual remaining oil saturation starts to deteriorate. One explanation for this is, of course, that the change in porosity during test 3.4 has not been included in the model. Incorporation of the porosity changes will be required to improve the remaining oil saturation model. Still it is interesting to notice that the actual remaining oil saturation just downstream of the low-porosity band, i.e. closest to the outlet, in tests 3.6 to 3.8 is lower than the expected remaining oil saturation.

The latter observation indicatives that the increased porosity contrast leads to the continuous oil phase to be disrupted at the downstream end of the low-porosity band. This is because this point in the plug now reaches the remaining oil saturation prior to any other point in the plug. The consequence of this is that the average remaining oil saturation at the termination of the waterflood is higher than expected because some movable oil is capillarytrapped behind the layer of chalk that has already achieved the level of remaining oil saturation.

Remobilization of the capillary-trapped oil requires that the pressure drop across the trapping interval, containing discontinuous oil, exceeds the capillary entry pressure.

\subsection{Surfactant Injection Tests}

One set of experiments (1.1 and 1.2) was carried out to study the displacement of oil by a surfactant solution in this very tight chalk. In these two floods the plug was initially completely oil saturated. This was deliberately done in order to have identical conditions. The main objective was to study the flow pattern and recovery mechanisms. The surfactant is described above and the properties of the system are summarised in Table 3. 
Tảblè 3. Surfactant flooding test

\begin{tabular}{||l|l|l||}
\hline $\begin{array}{l}\text { Test } \\
\text { no. }\end{array}$ & $\begin{array}{l}\text { Oil } \\
\text { viscosity } \\
\text { (cP) }\end{array}$ & $\begin{array}{l}\text { Oil-water } \\
\text { interfacial } \\
\text { tension } \\
\text { (mN/m) }\end{array}$ \\
\hline $1.1($ Oil-1) & 1.55 & 29.07 \\
\hline $1.2($ Oil-1) & 1.55 & 3.45 \\
\hline
\end{tabular}

Several interesting phenomena are observed. Based on the mass balance of injected and produced fluids, the two floods, i.e. 1.1 and 1.2, gave the same recovery, which was slightly more than $60 \%$. From the average saturation in parallel, vertical cross-sections along the plug the recovery obtained by $\mathrm{x}$-ray CT-scanning was the same. A preliminary conclusion could be that the surfactant had no effect at all.

But the CT-scans give a more information which leads to a more detailed conclusion. First of all a dramatic variation in the porosity is observed within plug 1. This enhances the effects described above for plug 3. Also the breakthrough time and the pressure drop revealed big differences between the two processes. Due to the strong variation in the porosity within the plug, the action of capillary and viscous forces was very clear.

In the water injection test the water almost completely displaced the oil in the tight zones and left high oil saturations in the most porous zones. The water front clearly reached the outlet end of the plug long before water breakthrough. The final result was a very uneven distribution of the remaining oil and a very strong capillary end effect. In the surfactant injection test the interfacial tension was lowered by a factor of almost 10 . The imbibition was not dominating the microscopic flow pattern in the plug, which led to a much more even remaining oil saturation. The remaining oil saturation after the water injection varied between 0.03 and 0.8 whereas for the surfactant injection it varied between 0.3 and 0.5 . Within the accuracy of the measurements, breakthrough was observed when the displacing front reached the outlet end of the plug. The two processes of obtaining $60 \%$ recovery were totally different in nature.

\section{DISCUSSION}

Test conditions (up stream pressure, flow rates, fluid viscosities, oil-water interfacial tension, etc.) for the discussed tests in this paper do not deviate significantly from typical test conditions applied in standard core analyses of chalk samples. The observations made in connection with the discussed tests can therefore be expected to be general rather than specific for the discussed tests.

The tested chalk plugs can in general be considered to represent a typical highporosity/high-permeability chalk. In the case of Danian chalk or low porosity Maastrichtian chalk even larger deviations from the basic assumptions can be expected because of the lower permeability and higher capillary entry pressure for these rock types. Therefore the studied test examples cannot be considered to be a "worst case" example.

The consequence of the observations is therefore that many core analysis programmes aimed at defining the potential of a new oil recovery process may have produced incorrect results because the test results have been affected by the test conditions.

\section{CONCLUSIONS}

1. Three factors will to a large extent control the initial oil and water distribution as well as the remaining oil saturation to water injection in small chalk core samples. These factors are the capillary end effects at the inlet and the outlet of the plug, and the small-scale heterogeneities inside the plug.

2. The combination of the uneven initial fluid distribution and the capillary end effects during waterflooding makes the interpretation of the outcome of present core analysis procedures very complex. 
3. The effect of the above-mentioned three factors is dramatically reduced in surfactant injection processes.

4. The traditional concept of capillary number is not applicable to the surfactant injection process in the tight chalk. The remaining oil is distributed in a totally different way when the capillary forces are reduced even when the capillary number is only increased by a factor of ten. This has been shown for the case where the initial water saturation is zero.

\section{ACKNOWLEDGEMENT}

The authors want to thank Mærsk Olie og Gas AS, Shell and Texaco as well as the Danish Technical Research Council for financial support and permission to publish the results. 